\title{
Comparative Analysis of Terrestrial Semi-automatic and Automatic Photogrammetry in 3D Modeling Process
}

\author{
Sonja Krasić • Petar Pejić
}

Published online: 13 May 2014

(C) Kim Williams Books, Turin 2014

\begin{abstract}
Photogrammetry is a method of producing models of three-dimensional spatial structures based on two-dimensional photos, using a diverse range of software packages. It is currently being used for making and recording 3D models of structures and spatial entities of cultural architectural heritage. In this study, using a comparative method, the terrestrial semi-automatic digital photogrammetric method is analysed, as well as the terrestrial automatic method of photogrammetry. Both methods are presented in the case study of 3D models of the remains of the Nis Palace with an Octagon dating back to the Roman period and located on the town's fields.
\end{abstract}

Keywords Roman architecture - Perspective - Automation - CAAD . Computer technology $\cdot$ Geometry $\cdot$ Modeling $\cdot$ Projective geometry

\section{Introduction}

Taking into consideration old buildings and sites is the first step in getting an idea of a way of watching, restoring and reconstructing them, i.e. of having architectural heritage protected (Pejic and Krasic 2012b:111). Methods and techniques of recording constructions and spatial entities have an array of possibilities, naturally starting from the simplest manual recordings up to modern technologies which provide options of virtual presentations of parts of a construction and its whole, or of old historical constructions.

\footnotetext{
S. Krasić · P. Pejić ( ()

Faculty of Civil Engineering and Architecture, University of Niš, Nis, Serbia

e-mail: petar.pejic@gaf.ni.ac.rs

S. Krasić

e-mail: sonjak@gaf.ni.ac.rs
}

(virkhäuser 
One of the methods of creating a 3D construction model is the photogrammetric recording method (Venkat and Kriti 2008; Barazzetti et al. 2010; Hinterstoisser et al. 2010; Wefelscheid et al. 2011; Pejic and Krasic 2012a). Digital photogrammetry is the primary technique for the image data processing (Manferdini and Remondino 2010). For such an application of photogrammetry, at least two photographs of the same building are required, as well as the exact distance between two points visible in at least one photograph. Basic categories of photogrammetryterrestrial and aerial-follow a criterion of a referential point position. Ground photogrammetry is taken from a point on or near the surface of the ground, and aerial photogrammetry is taken from the air, and in most cases from an airplane or a satellite (Pejic and Krasic 2012b).

This study presents a comparative analysis of the terrestrial semiautomatic (Pejic et al. 2012; Wirtz et al. 2012) and automatic photogrammetry (Irschara et al. 2010; Del Pizzo and Troisi 2011; Kersten and Stallmann 2012; Remondino et al. 2012; Fraser 2012), based on the study of creating a 3D model of the remains of the Palace with an Octagon in Nis, Serbia. It was done using the semiautomatic photogrammetric method, "Tgi3D" (http://www.tgi3d.com/) programme and "SketchUp 8" (http://www.sketchup.com/) along with the automatic photogrammetric method supported with "123D Catch" (http://www.123dapp.com/catch).

The objective of the study is to figure out both good and bad sides of the two photogrammetric methods applications on creating constructions and spatial entities models through the given comparison, depending on modelling criteria demands, geometric accuracy and quality of visual aspects, physical features of an object, a site surrounding, as well as available financial support (Pejic and Krasic 2012b).

\section{Criteria for Choosing a Certain Digital Recording Method}

Methods and techniques of digital recording are necessary means of protection and presentation of present day architectural heritage. The protection of a construction should be started before its decay, transformation or any other change, while a global web presentation has become an essential ingredient of the touristic offerings of a town. Considering a variety of constructions and sites which are to be recorded, we can have numerous methodological and technological approaches in the digital recording. The choice depends on the following:

- The aim of a study the point of digitizing defines a demanding quality and a way of recording. The recording process can be done with the purpose of getting information about structure, decay analysis, 2D and 3D construction presentation, virtual reality creation, construction value estimation, etc.

- Geometric accuracy and visual quality demands different techniques create different degrees of accuracy. Some tasks demand a high level of visual quality and that can be obtained by applying matching texture of digital recording.

- Physical features of a construction and its surrounding parameters such as a construction and the size of its surroundings and their accessibility define a way 
and type of recording. There are different methods for different sizes and levels of accessibility.

- Financial support successful digital methods application depends on high quality equipment and good recording time estimation (Ortiz et al. 2006)

\section{Case Study of Nis Palace with an Octagon 3D Model Creation}

The Nis Palace with an Octagon (Fig. 1) is located out of the walls of Ottoman Fortress which still exists on the town's fields, and it is thought to have been located within the walls of a Roman Fortress which used to exist on the site. It dates to the time of Constantine (fourteenth century AD) and it is supposed that it used to be a representative construction considering some mosaics, a floor and wall heating system and a natural room light system discovered by archeologists.

\section{Semiautomatic Photogrammetry Model Creation}

Creating a Palace with an Octagon 3D model started with taking photos of the palace from different angles with a digital Canon EOS 600D camera. Since ancient buildings' walls usually do not meet at a $90^{\circ}$ angle, in order to get a model of the Palace with an Octagon the "Tgi3D PhotoScan" calibration software and a free version of the "SketchUp 8" software package for 3D model creation were used.

Four photos of various angles of the Palace were imported into the "Tgi3D PhotoScan" programme. In each of the photos, a user finds, marks and connects a specific point of the construction which is the subject of interest. This was repeated 50 times with the Palace with an Octagon photos (Fig. 2) in order to get better accuracy in the connection. All points of calibration were set so tolerance was less than 0.5 pixels. Photos connected in that way were exported as a "SketchUp" file ready for further processing.

Having opened the previously created file in the "SketchUp" programme package, a global coordinate system was set so its starting point was on the Palace floor elevation and one axis matched the direction of the wall and the vertical axis
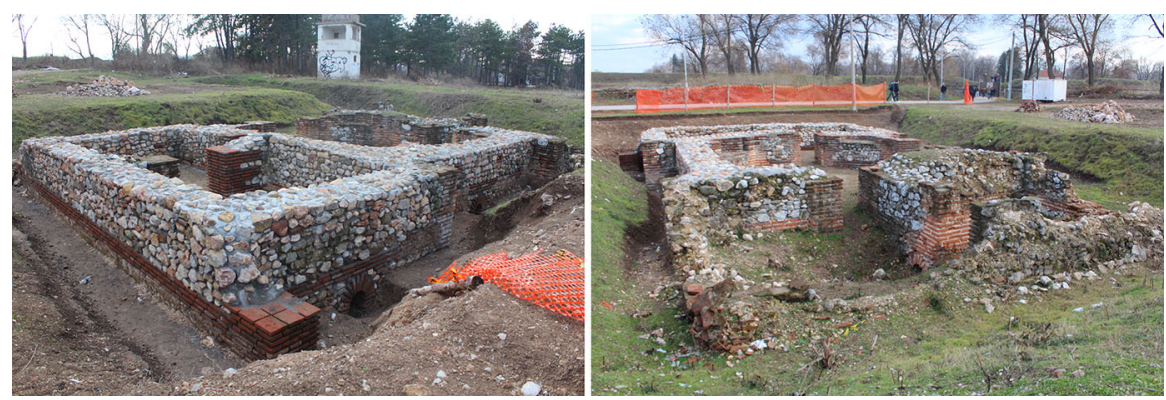

Fig. 1 The Nis Palace with an Octagon 


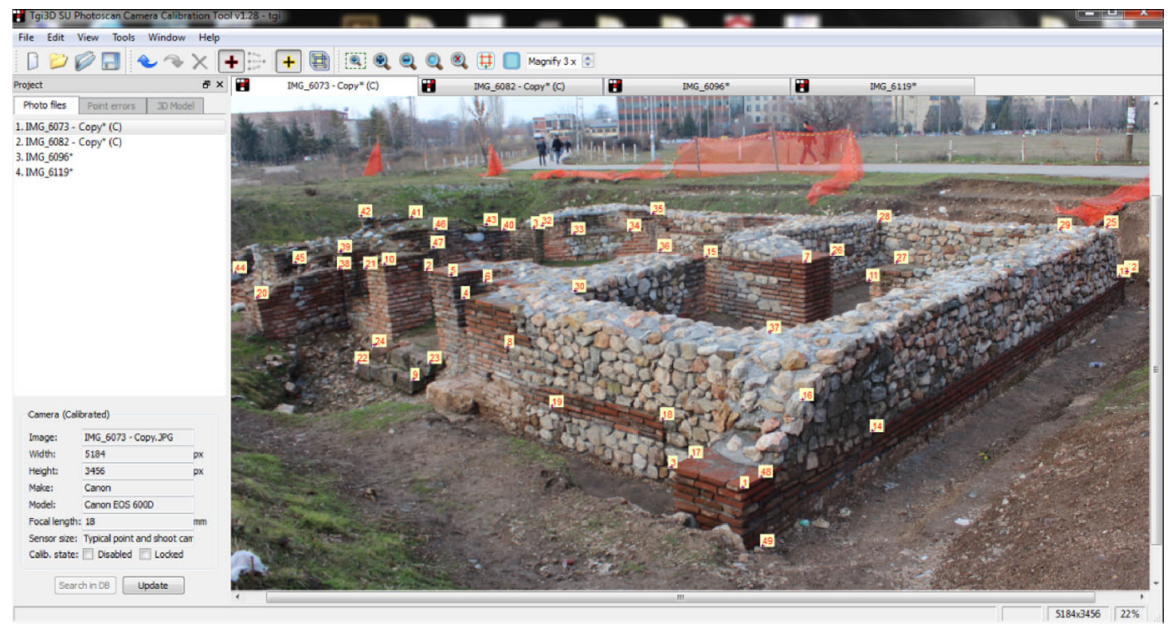

Fig. 2 Calibration

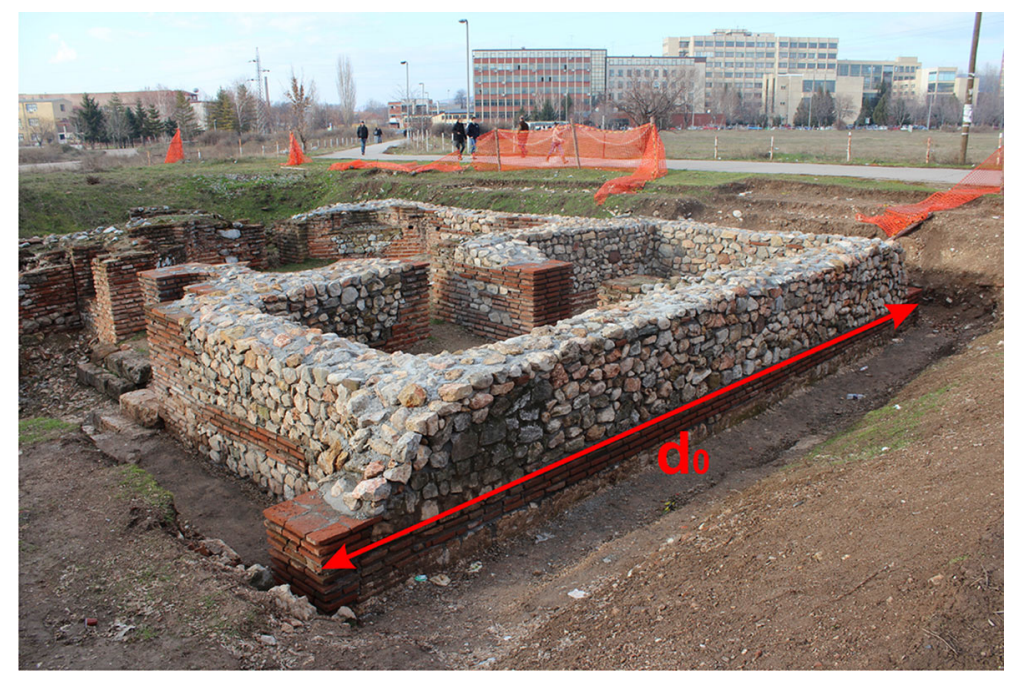

Fig. 3 Reference length

remained vertical. Then considering key points and photos of four different angles, and using basic "SketchUp" modelling tools, drawings of all surfaces of the palace were made. After that the texture of the photos was constructed on the surfaces of the model which made it look quite realistic. The outer wall length $\mathrm{d}_{0}$ (Fig. 3) was taken as a reference for model scaling which was done using the "SketchUp" tool "Tape Measure" in the rate 1:1. 


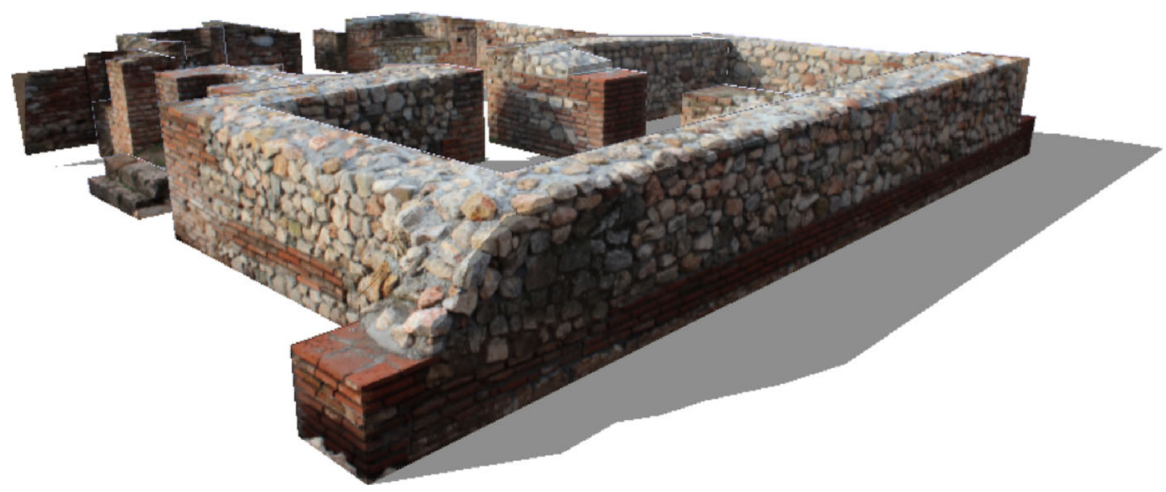

Fig. 4 Final 3D model

The final result of the whole process is a photo realistic 3D "solid" model (Fig. 4) of the Nis Palace with an Octagon. Human factor had a great influence on simplification of the surfaces, so the template is not detailed, but saved "*.skp" file is $1.4 \mathrm{MB}$ only. Such a model is easy to share online and to present to all Net users over Google Earth and 3D Warehouse services which the "SketchUp" is directly connected to.

\section{Automatic Photogrammetry Model Creation}

Creating a Palace with an Octagon 3D model started with taking photos of the palace from different angles with a digital Canon EOS 600D camera. The whole process of the automatic photogrammetry and the model creation was done using "1233D Catch", a free software package.

For getting a model using automatic photogrammetry it is necessary to have a large number of photos. That's why we had 93 photos of the Palace with an Octagon to create its model using the automatic photogrammetry method. Photos were taken of the construction from points around it which were at a $15^{\circ}$ distance, as well as within the very construction (Fig. 5) so all walls were processed. Those photos were imported into the "123DCatch" software package.

Since a lot of data has to be processed the "123D Catch" sends all of it to the online server. In other words the "123D Catch" represents a user interface programme for data input and results check, while calibration of photos and 3D model creation takes place somewhere else. When the processing is over the " $123 \mathrm{D}$ Catch" downloads a readymade 3D model of the Palace in an unknown rate, so at the moment it is necessary to select two points which define a referent length and type a distance $\mathrm{d}_{0}$ (Fig. 6) so we can get a model in its real size.

The influence of the human factor is minimized here because some activities done in the "123D Catch" programme are reduced to importing photos and scaling a model. The whole process is automated and no people are needed to be involved.

The final result of this process is a photorealistic 3D mesh surface model of the Palace with an Octagon (Fig. 6). A model created that way is very detailed and 


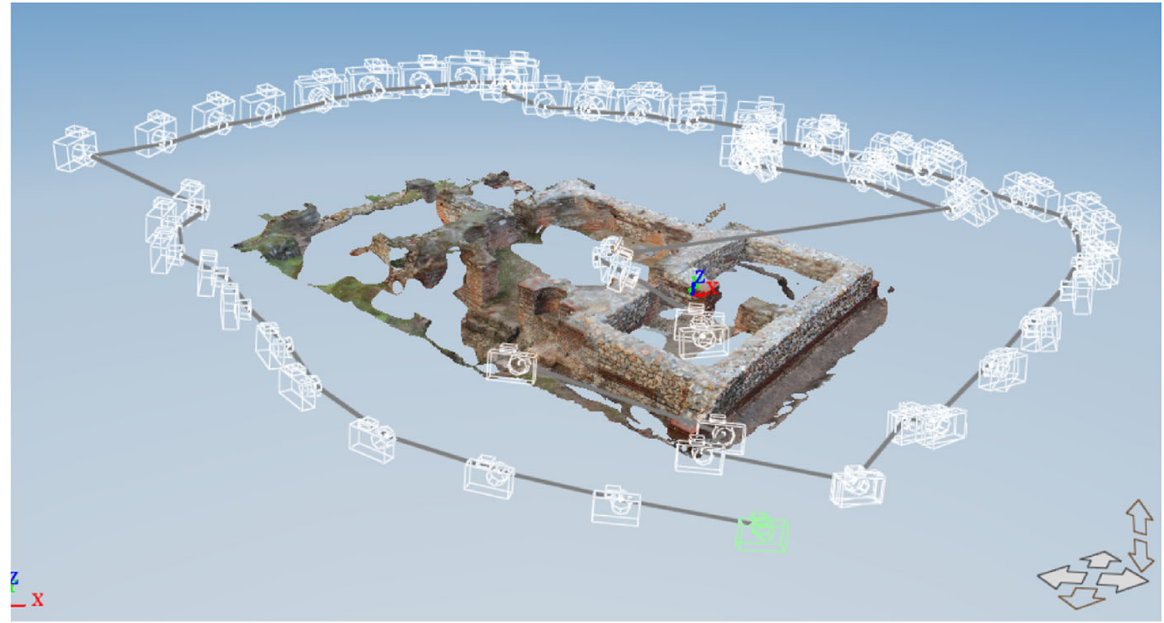

Fig. 5 Final 3D model

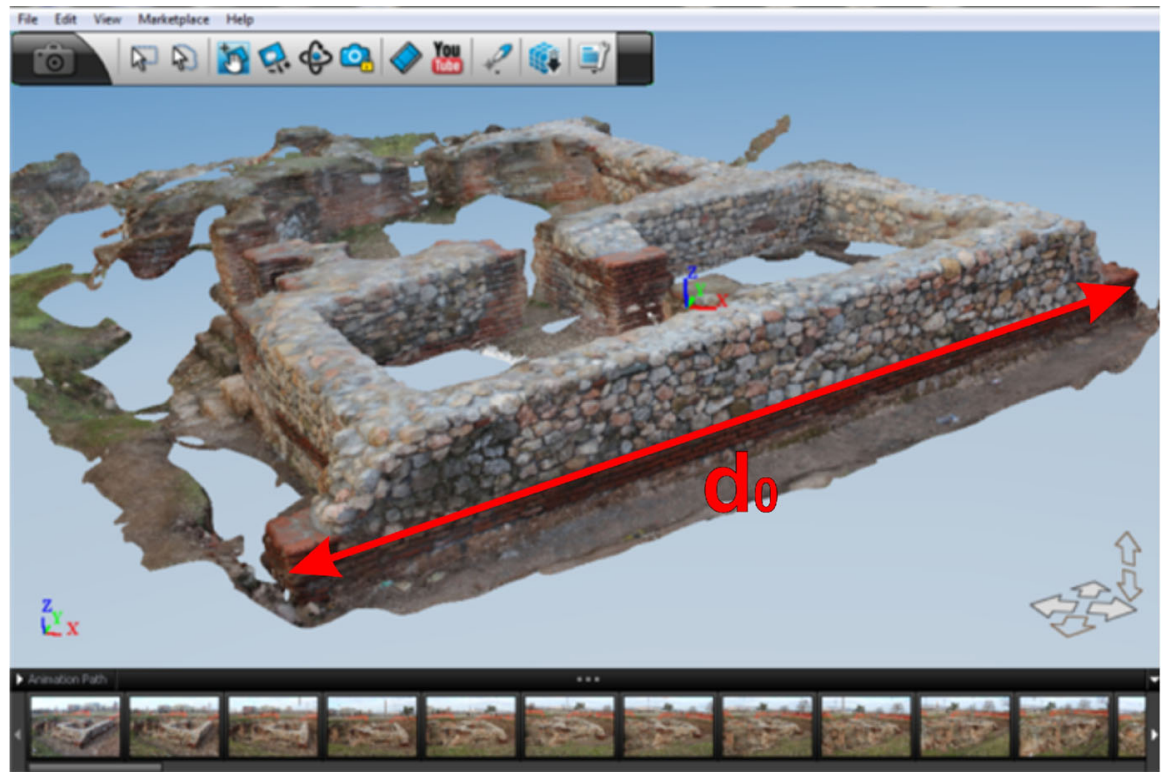

Fig. 6 Surfaces drawing

precise. For the sake of the comparison of the final file size to the size of the file created using the semiautomatic photogrammetric method, the model was exported as an "*.obj" file. It was then imported into SketchUp and saved as a "*.skp" file, $45 \mathrm{MB}$ in size. A model of that size is not suitable for web presentations, but owing to its precision it is very good for digital recording of constructions and spatial entities of architectural heritage. 


\section{Results and Discussion}

For the sake of comparison of the two previously described methods, control measuring of 13 distances $\left(\mathrm{d}_{1}-\mathrm{d}_{13}\right)$ on the Palace with an Octagon was done (Fig. 7). Distance measuring was also done between the same points on the final model which was created using the semiautomatic and automatic photogrammetric methods (Fig. 8).

The next step was getting percentage of tolerance of all distances on the model itself related to the real length for both models created using two different photogrammetries and it is shown in tables (Table 1). An approximate percentage of tolerance of both methods apart from $\mathrm{d}_{0}$ distance is given at the bottom of the table and it is $4.84 \%$ for the semiautomatic and $1.77 \%$ for the automatic photogrammetry.

Tolerance related to the existing lengths compared to those obtained in some other researches (Erickson et al. 2013) is larger simply because stronger human impact, type of object and the level of its preservation are what matters there. In the process of model creation there were used neither coded targets nor markers ( $\mathrm{Li}$ and Liu 2010). In several fields such as architecture, archaeology and Cultural Heritage, coded targets cannot be employed (Remondino et al. 2012). In these cases, the tie point identification for the determination of the exterior orientation is more complex and needs to be solved, preferably, using fully automatic image matching procedures. On the other hand, the precise measurements of control points for the scaling and geo-referencing of the image block (absolute orientation) is still a manual (interactive) task (Remondino et al. 2012).

3D models of the Palace with an Octagon in Nis obtained using both semiautomatic and automatic photogrammetric methods have different levels of detailed geometry of an object. The model created using the semiautomatic method

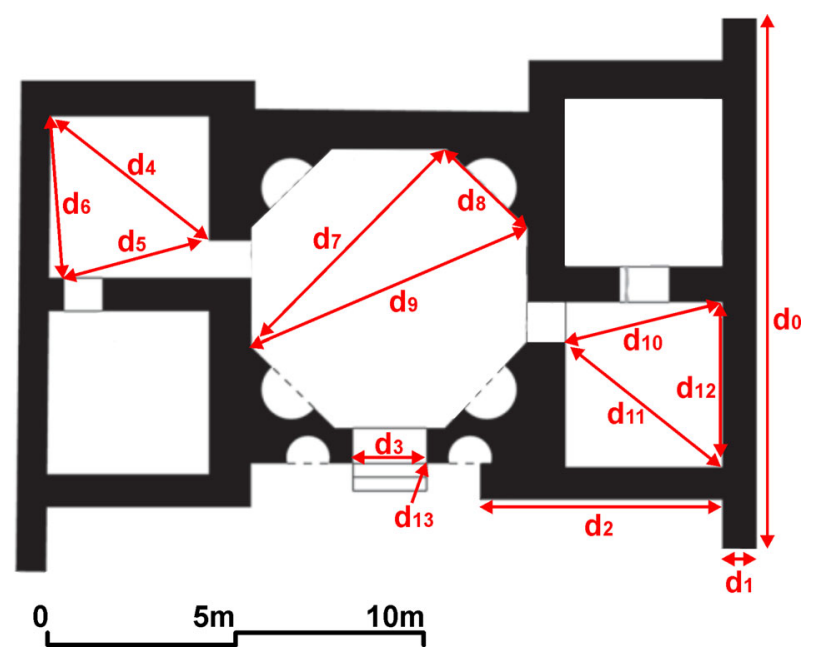

Fig. 7 Base of the palace with marked control distances 

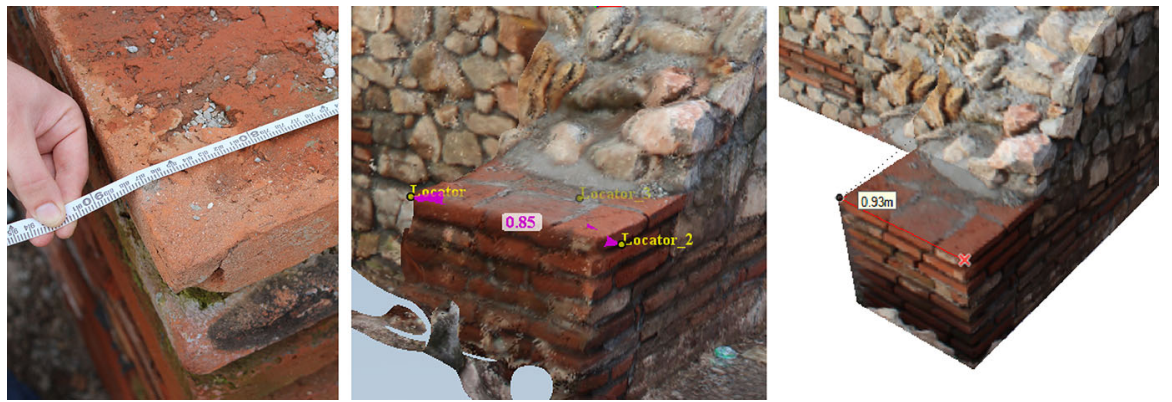

Fig. 8 Measuring distances on both the construction and the model

did not have its surfaces modelled in details, and its geometry was approximated. All that led to larger approximate tolerance in the model obtained using the semiautomatic photogrammetric method than it was in the model obtained using the automatic photogrammetric method.

To use the semiautomatic photogrammetry method it is necessary to have basic knowledge of perspective and infinity setting for octagonal constructions or photo connecting for those which are not octagonal. A person who creates a model has to know the tools for modelling which can be found in a software package if they want to get a 3D model. Model details and precision depend primarily on one's skill and the time they are ready to spend on the whole process. A final model is very realistic owing to photo textures, while digital files are of relatively very small size, so they are suitable for model presentations on some of the existing online services, i.e. Google Earth or 3D Warehouse.

The automatic photogrammetry does not demand from a person any previous knowledge of perspective, photogrammetry or 3D modelling. The complete process is automated, so a user should import photos only and afterwards they export from a programme a readymade $3 \mathrm{D}$ model.

Details and precision of a model are not related to any previous knowledge or time a user can spend on creating a 3D model. The final model is realistic and very detailed owing to photo textures, while digital files are very large and they are not suitable for web presentation.

Comparing previously described methods of terrestrial photogrammetries which helped us create 3D models of the construction using photos we can find both common and different elements of them.

Common elements of semiautomatic and automatic terrestrial photogrammetries

They both make suitable methods for recording architectural heritage of smaller sizes;

They both have known input data, photos and one length;

They can create photorealistic 3D models;

They use free software.

Different elements of semiautomatic and automatic terrestrial photogrammetries 
Table 1 Control measuring and distance tolerance on the model

\begin{tabular}{|c|c|c|c|c|c|}
\hline \multirow[t]{2}{*}{ Distance mark } & \multicolumn{3}{|l|}{ Length $(\mathrm{cm})$} & \multicolumn{2}{|c|}{ Tolerance related to real length $(\%)$} \\
\hline & $\begin{array}{l}\text { Real } \\
\text { (measured) }\end{array}$ & $\begin{array}{l}\text { Semiautomatic } \\
\text { photogrammetry }\end{array}$ & $\begin{array}{l}\text { Automatic } \\
\text { photogrammetry }\end{array}$ & $\begin{array}{l}\text { Semiautomatic } \\
\text { photogrammetry }\end{array}$ & $\begin{array}{l}\text { Automatic } \\
\text { photogrammetry }\end{array}$ \\
\hline $\mathrm{d}_{0}$ & 1,345 & 1,345 & 1,345 & 0.00 & 0.00 \\
\hline$d_{1}$ & 88 & 93 & 85 & 5.88 & 3.41 \\
\hline$d_{2}$ & 520 & 516 & 522 & 0.76 & 0,38 \\
\hline$d_{3}$ & 186 & 164 & 193 & 9.84 & 3.76 \\
\hline $\mathrm{d}_{4}$ & 523 & 497 & 544 & 4.87 & 2.10 \\
\hline $\mathrm{d}_{5}$ & 392 & 385 & 395 & 1.77 & 0.76 \\
\hline$d_{6}$ & 418 & 412 & 428 & 1.40 & 2.39 \\
\hline $\mathrm{d}_{7}$ & 715 & 698 & 708 & 2,40 & 0.98 \\
\hline $\mathrm{d}_{8}$ & 297 & 270 & 297 & 9.09 & 0.00 \\
\hline $\mathrm{d}_{9}$ & 715 & 686 & 736 & 3.94 & 2.93 \\
\hline $\mathrm{d}_{10}$ & 430 & 436 & 431 & 1.39 & 0.23 \\
\hline $\mathrm{d}_{11}$ & 532 & 558 & 535 & 4.86 & 0,56 \\
\hline$d_{12}$ & 415 & 446 & 430 & 7.21 & 3.61 \\
\hline $\mathrm{d}_{13}$ & 160 & 145 & 157 & 9.55 & 1.87 \\
\hline $\begin{array}{l}\text { Approximate } \\
\text { tolerance } \\
\text { value }\end{array}$ & & & & 4.84 & 1.77 \\
\hline
\end{tabular}

Table 2 Comparative display of elements of semiautomatic and automatic photogrammetries

\begin{tabular}{lcc}
\hline Elements important for photogrammetry & $\begin{array}{l}\text { Semiautomatic } \\
\text { photogrammetry }\end{array}$ & $\begin{array}{l}\text { Automatic } \\
\text { photogrammetry }\end{array}$ \\
\hline Time necessary for collecting data & + & - \\
Photoreality of a model & + & + \\
Price of software & + & + \\
Hardware demands & + & + \\
Previous knowledge of photogrammetry & - & + \\
Previous knowledge of 3D modelling & - & + \\
Details of model & - & + \\
Size of model & + & + \\
Human factor & - & - \\
Web presentation & + & + \\
\hline
\end{tabular}

They need different numbers of necessary photos for creating a model; Previous knowledge and competence of a person who wants to create a model is required;

Geometric nature of model;

Details of 3D model;

Size of file;

Suitability for a web presentation. 
Based on important elements in the process of the described photogrammetries, Table 2 shows the comparison between the methods with obvious positive $(+)$ and negative $(-)$ values of the process.

\section{Conclusion}

Creation of digital models for recording architectural heritage is a very efficient and quality way of protection and presentation which is possible owing to availability of various modern technologies. That's why a method of terrestrial photogrammetry is used for collecting data without previous contact with a construction. By using this method it is possible to create very accurate digital models of constructions and spatial entities. It provides unlimited access to cultural constructions which is important for doing scientific research in the purpose of architectural heritage protection.

The difference between the models created using both semiautomatic and automatic photogrammetries is of a geometric nature, too, i.e. the first is a solid model and the second is with a mesh surface. It requires processing that can make it functional for different uses.

The terrestrial automatic photogrammetry is an improvement on existing methods and processes of creating digital 3D models. It represents one of the final steps in photogrammetric processing evolution. Bad sides of the automatic photogrammetry compared to semiautomatic photogrammetry are time necessary to be spent on taking photos of a construction, size of files and a less possibility for web presentation. Through with further development of this method as well as with Net development the automatic photogrammetry will prevail in the near future, putting aside the semiautomatic one. For the time being the semiautomatic photogrammetry is more widely used although it takes more time, demands competence and experience in modelling, is possible to optimise files and has a quality of model photoreality necessary for a web presentation.

\section{References}

Barazzetti, L., M. Scaioni, and F. Remondino. 2010. Orientation and 3D modeling from markerless terrestrial images: combining accuracy with automation. The Photogrammetric Record 25(132): 356-381.

Del Pizzo, S., and S. Troisi. 2011. Automatic orientation of image sequences in cultural heritage. ISPRS Trento 2011 Workshop, 293-300. Trento, Italy.

Erickson, M., Bauer, J., and W. Hayes. 2013. The accuracy of photo-based three-dimensional scanning for collision reconstruction using 123d catch, SAE Technical Paper 2013-01-0784, 1-10.

Fraser, C. 2012. Automatic camera calibration in close-range photogrammetry. In Proceedings: ASPRS 2012, Sacramento, CA, USA.

Hinterstoisser, S., Lepetit, V., Ilic, S. and P. Fua. 2010. Nassir NavabDominant orientation templates for real-time detection of texture-less objects. Computer Vision and Pattern Recognition (CVPR) Conference. 2257-2264.

Irschara, A., Kaufmann, V., Klopschitz, M., Bischof, H., and F. Leberl. 2010. Towards fully automatic photogrammetric reconstruction using digital images taken from UAVs. In Proceedings 
International Society For Photogrammetry And Remote Sensing Symposium, 100 Years ISPRSAdvancing Remote Sensing Science.

Kersten, T.P., and D. Stallmann. 2012. Automatic texture mapping of architectural and archaeological $3 D$ models, 273-278. Melbourne: XXII ISPRS Congress.

Li, L., and M. Liu. 2010. Research on decoding method of coded targets in close-range photogrammetry. Journal of Computational Information Systems 6: 2699-2705.

Manferdini, A.M., and F. Remondino. 2010. Reality-based 3D modeling, segmentation and web-based visualization. EuroMed 2010, LNCS 6436: 110-124.

Ortiz, P., Sánchez, H., Pires, H., and Pérez, J.A. 2006. Experiences about fusioning 3D digitalization techniques for cultural heritage documentation. In Proceedings of the ISPRS Commission $V$ Symposium-"Image Engineering and Vision Metrology", Dresden: 1-2.

Pejic, P., and S. Krasic. 2012a. Creation of three-dimensional architectural models from photographs, 136-142. Sofia: International Convention PHOTOCOLOR III.

Pejic, P., and S. Krasic. 2012b. Modern methods of three dimensional presentations of the building heritage. IV International Symposium For Students Of Doctoral Studies In The Fields Of Civil Engineering, Architecture And Environmental Protection. 111-119. 27-28 September 2012, Nis, Serbia.

Pejic, P., Krasic, S., and O. Nikolic. 2012. Creation of architectonic 3D models by contemporary photogrammetry methods. International Conference MoNGeometrija 2012, 289-297. Faculty of Technical Sciences, University in Novi Sad, Serbia.

Remondino, F., S. Del Pizzo, T.P. Kersten, and S. Troisi. 2012. Low-cost and open-source solutions for automated image orientation-a critical overview. Progress in Cultural Heritage Preservation Lecture Notes in Computer Science 7616: 40-54.

Venkat, D., and C. Kriti. 2008. Mathematical foundation of photogrammetry. Lectures, University of Texas, Arlington.

Wefelscheid, C., Hansch R., and O. Hellwich. 2011. Three-dimensional building reconstruction using images obtained by unmanned aerial vehicles. ISPRS Zurich 2011 Workshop, 183-188. Zurich, Switzerland.

Wirtz, S., Decker, P., and D. Paulus. 2012. Semiautomatic generation of semantic building models from image series. In Proceedings: SPIE 8290, Three-Dimensional Image Processing (3DIP) and Applications II, 829019 (February 9, 2012).

Sonja Krasić is Associate Professor in the Department of Visual Communication, Faculty of Civil Engineering and Architecture, Niš, Serbia. Dr. Krasic undertakes research in the field of descriptive geometry and into applications of photogrammetry in architecture.

Petar Pejić is a PhD student (Architecture) at the Faculty of Civil Engineering and Architecture, Niš, Serbia, and a teaching assistant in the Department of Visual Communication in that faculty. Pejic undertakes research into applications of photogrammetry and augmented reality in architecture. 